\title{
Dose Sparing Effects of Butorphanol and Diazepam or Midazolam Premedication on Propofol Total Intravenous Anaesthesia in Dogs
}

\author{
Surbhi K. Tyagi ${ }^{1 *}$, Manisha P. Pratap ${ }^{2}$, D.N. Suthar ${ }^{3}$, R.H. Bhatt ${ }^{4}$, S.K. Jhala ${ }^{3}$, \\ V.S. Dabas ${ }^{3}$ and Divya Chaudhari ${ }^{5}$ \\ ${ }^{1}$ Department of Veterinary Surgery \& Radiology, COVAS, SVPUAT-Meerut, INDIA \\ 2 Private Practitioner, Palanpur, Gujarat, INDIA \\ ${ }^{3}$ Department of Veterinary Surgery \& Radiology, C.V.S.C, NAU-Navsari, Gujarat, INDIA \\ ${ }^{4}$ Teaching Veterinary Clinical Complex, C.V.S.C, JAU-Junagarh, Gujarat, INDIA \\ ${ }^{5}$ Department of Animal Husbandry, Dang, Gujarat, INDIA \\ *Corresponding author: SK Tyagi; E-mail: surbhiivri@gmail.com
}

Received: 26 Aug., 2020

Revised: 18 Sept., 2020

Accepted: 22 Sept., 2020

\begin{abstract}
The objective of the study was to evaluate \& compare the dose sparing effect of atropine-butorphanol-diazepam (A-B-D) and atropine-butorphanol-midazolam (A-B-M) combination as basal anaesthesia on induction and maintenance dose of propofol used as Total intravenous anaesthesia (TIVA) in dogs. Thirteen dogs were randomly divided into group I ( $\mathrm{n}=7)$ \& group II ( $\mathrm{n}=6$ ), wherein atropine, butorphanol, diazepam/midazolam were given as preanaesthetic drugs, while, induction and maintenance of anaesthesia was done with propofol. Systolic blood pressure, diastolic blood pressure, mean arterial pressure and peripheral capillary oxygen saturation $\left(\mathrm{SpO}_{2}\right)$ were recorded after induction of anaesthesia, at regular 15 minute intervals, up to 45 minutes. The physiological parameters were recorded before giving any drug and thereafter at regular 15 minute interval post induction. In midazolam-butorphanol group, the induction and maintenance dose of propofol was non-significantly higher than in diazepam-butorphanol group. Both diazepam-butophanol and midazolam-butorphanol have dose sparing effect on induction and maintenance dose of propofol, however, diazepam-butorphanol combination is slightly better than midazolam-butorphanol combination.
\end{abstract}

\section{HIGHLIGHTS}

(0 The dose sparing effect of basal anaesthetic combinations atropine-butorphanol-diazepam (A-B-D) and atropine-butorphanolmidazolam (A-B-M) on induction and maintenance dose of propofol was compared.

( Both the combinations reduced the dose of propofol with no significant difference between midazolam or diazepam as preanaesthetic.

Keywords: Butorphanol, diazepam, dogs, midazolam, propofol, TIVA

Total intravenous anaesthesia (TIVA) is a widely used technique for induction and maintenance of general anaesthesia, especially in field conditions and set ups where in surgical procedures can be done with minimal facilities. For induction of general anaesthesia, intravenous anaesthetic drugs are usually first administered as a large bolus and for maintenance of anaesthesia drugs can be administered in continuous lower dosages either by Repeated Intravenous bolus (RIB), Continuous
Intravenous infusion/ constant rate infusion (CRI), or Target-controlled infusion (TCI) (Beths, 2008; Waelbers et al., 2009).

Premedication of animals before induction of anaesthesia

How to cite this article: Tyagi, S.K., Pratap, M.P., Suthar, D.N., Bhatt, R.H., Jhala, S.K., Dabas, V.S. and Chaudhari, D. (2020). Dose sparing effects of butorphanol and Diazepam or Midazolam premedication on propofol total intravenous anaesthesia in dogs. J. Anim. Res., 10(5): 777 781.

Source of Support: None; Conflict of Interest: None क्ष 
provide significant advantages in terms of intraoperative cardiovascular stability, perioperative analgesia and quality of recovery (Lemke, 2007) in addition may reduce the dose of general anesthetic. A combination of 2 or 3 drugs is usually administered to achieve the desired effect. Anticholinergics like atropine sulphate is frequently used as preanaesthetic agent to inhibit excessive salivation and respiratory secretions, perioperatively to manage bradycardia and atrioventricular (AV) block associated with surgical manipulation (Thurmon and Short, 2007). Butorphanol tartrate is a centrally acting agonist antagonist type of opioid that provides sedation, short duration analgesia and reduces the dose of intravenous anaesthetic for induction (Koc et al., 2006).

Diazepam is a water insoluble benzodiazepine used as sedative, anxiolytic, muscle relaxant, hypnotic, appetite stimulant and anticonvulsant. Midazolam, also a benzodiazepine, is a water soluble, anxiolytic, hypnotic, anticonvulsant, skeletal muscle relaxant, sedative with cardiovascular sparing effects and approximately 3 to 4 times more potent than diazepam (Kushwaha et al., 2012). Propofol (1\%) is a non-barbiturate, non-steroid, ultra short acting intravenous induction and maintenance anaesthetic agent with a rapid smooth induction and a rapid recovery in dogs and cats (Vannatta and Rex, 2006; Jimenez et al., 2012; DeVries et al., 2013).

In contrast to the inhalant agents, TIVA techniques can be used in the field conditions, without specialized instrumentation. The objective of the study was to evaluate \& compare the dose sparing effect of diazepambutophanol and midazolam-butorphanol combination as basal anaesthesia on induction and maintenance dose of propofol used as Total intravenous anaesthesia (TIVA) in dogs.

\section{MATERIALS AND METHODS}

Thirteen client owned dogs presented for various surgical procedures were divided randomly into group I (Butorphanol-Diazepam group, $\mathrm{n}=7$ ) and II (ButorphanolMidazolam group, $n=6$ ). The animals were kept off feed for 12 hours before surgery and water was withheld for 6 hours. The dogs were pre-medicated with atropine sulphate (@ $0.04 \mathrm{mg} / \mathrm{kg}$ body wt.) followed by butorphanol (@ $0.02 \mathrm{mg} / \mathrm{kg}$ body wt. IV) after 5 minutes followed by an immediate injection of diazepam (@ $0.5 \mathrm{mg} / \mathrm{kg}$ body wt. IV in group I) or midazolam (@ $0.2 \mathrm{mg} / \mathrm{kg}$ in group II). Induction was made after $5 \mathrm{~min}$ of the preanaesthetic medication by propofol @ 4-8 mg/kg IV bolus "till effect". Maintenance was done by repeated intravenous bolus (RIB) injection of propofol (Table 1).

The dose of propofol required for induction of anaesthesia was calculated in milligram per kilogram $(\mathrm{mg} / \mathrm{Kg})$ as well as the maintenance dose was calculated per animal in milligram per kilogram per minute $(\mathrm{mg} / \mathrm{kg} / \mathrm{min})$. The time from which maintenance of anaesthesia was stopped to the re-appearance of pedal reflex was recorded as recovery time and was noted.

Table 1: Anaesthetic protocols used in group I \& II

\begin{tabular}{lll}
\hline Groups & Preanaesthetics & $\begin{array}{l}\text { Induction \& } \\
\text { Maintenance }\end{array}$ \\
\hline I & Atropine Sulphate @ 0.02 & $1 \%$ Propofol @ 4-8 \\
$(\mathrm{n}=7)$ & IM+Butorphanol @ $0.2 \mathrm{IV}+$ & $\mathrm{mg} / \mathrm{kg}$ BW (till effect, \\
& Diazepam @ 0.5 mg/kg BW IV & IV.) \\
$\mathrm{II}$ & Atropine Sulphate @ 0.02 & $1 \%$ Propofol @ 4 - 8 \\
$(\mathrm{n}=6)$ & IM+Butorphanol @ $0.2 \mathrm{IV}+$ & $\mathrm{mg} / \mathrm{kg}$ BW (till effect, \\
& Midazoalm @ 0.2 mg/kg BW IV & IV.) \\
\hline
\end{tabular}

Physiological parameters like rectal temperature (RT${ }^{0} \mathrm{C}$ ), pulse rate (beats/min), respiratory rate (RR-breaths/ $\mathrm{min}$ ), systolic blood pressure (SBP-mm of $\mathrm{Hg}$ ), diastolic blood pressure (DBP-mm of $\mathrm{Hg}$ ), mean arterial pressure (MAP-mm of $\mathrm{Hg}$ ) and arterial oxygen saturation $\left(\mathrm{SpO}_{2} \%\right)$ were recorded by multipara monitor (Vital signs monitor, BM5 VET, Bionet Company Ltd, Korea) after induction of anaesthesia with propofol and thereafter at regular 15 minute time interval or till the end of the surgery.

Venous blood samples were collected for hematobiochemical estimation, after induction of anaesthesia and thereafter, at every 15 minute interval, till end of the surgery for estimation of haemoglobin $(\mathrm{g} / \mathrm{L})$ DLC (\%), TLC (x10-9/L) and PCV (L/L) using automatic haemato-analyzer. Estimation of blood glucose $(\mathrm{mg} / \mathrm{dL})$ was estimated by using glucometer, whereas, plasma urea nitrogen $(\mathrm{mmol} / \mathrm{L})$ and creatinine $(\mu \mathrm{mol} / \mathrm{L})$ was estimated using standard diagnostic kits using semi-automatic biochemical analyser.

\section{STATISTICAL ANALYSIS}

Analysis of variance (ANOVA) and Duncan's multiple range tests (DMRT) were used to compare the means at 
different intervals between two groups. Paired " $t$ " test was used to compare the mean values at different levels with their respective base value in each group.

\section{RESULTS AND DISCUSSION}

In group I (diazepam-butorphanol) the mean and S.E. dose of propofol for induction (Fig. 1) came as $3.58 \pm 0.29 \mathrm{mg} /$ $\mathrm{kg}$ and was non-significantly $(\mathrm{P} \leq 0.05)$ lower than in group II (midazolam-butorphanol) which was calculated as 4.02 $\pm 0.10 \mathrm{mg} / \mathrm{kg}$. Likewise, the maintenance dose of propofol (Fig. 2) was also non-significantly $(\mathrm{P} \leq 0.05)$ higher than in group II $(0.27 \pm 0.03 \mathrm{mg} / \mathrm{kg} / \mathrm{min}$. $)$ than in group I $(0.18 \pm$ $0.03 \mathrm{mg} / \mathrm{kg} / \mathrm{min}$.). The recovery time of group I was nonsignificantly $(\mathrm{P} \leq 0.05)$ higher than that of group II (Fig. 3).

A significant reduction in the dose of propofol required for tracheal intubation (post induction of anaesthesia) was reported in diazepam and midazolam premedicated cats (Rebecca and Kate, 2015). Sano et al., 2003 also reported a considerable reduction in the induction dose of propofol administered with butorphanol and benzodiazepine as preanaesthetic drugs, similar to our findings.

The rectal temperature slowly and gradually decreased in both the groups after induction of the anaesthesia. Post anaesthetic hypothermia observed may be the result of peripheral vasodilatation, reduced BMR, inhibition of skeletal muscle movement and depression of the thermoregulatory centre due to interactive actions of different anaesthetic agents as well as increased heat dissipation and heat loss through respiratory system (Khandekar et al., 2015). The pulse rate increased in both the groups but the increase was gradual with no difference between the groups at different time intervals. An increase in heart rate may be due to the effect of the propofol as also reported in earlier references (Surbhi et al., 2010; Suthar et al., 2018). Respiratory rate also showed a decreasing trend in both the groups with a more significant decrease in group II, although no significant difference was observed between the two groups. The respiratory depression observed might be due to the combined effect of butorphanol (Kuo et al., 2004), and propofol (Mutoh et al., 1997). Mean arterial pressure values increased nonsignificantly in both the groups with no difference between group I and II. However, a decrease in MAP was recorded in some earlier studies (Suthar et al., 2018). Oxygen saturation of haemoglobin $\left(\mathrm{SpO}_{2}\right)$ values remained within the normal range at different time intervals post induction in both the groups. Post induction an immediate endotracheal intubation was done. A decrease in $\mathrm{SpO}_{2}$ was reported by Surbhi et al., 2010; however, no such reduction in $\mathrm{SpO}_{2}$ has been reported in other studies (Suthar et al., 2018). The mean values of different physiological parameters have been summarized in table 2 .

Haemoglobin and PCV reduced non-significantly in both the groups, although all other haematological parameters exhibited a non-significant difference in mean values when compared at different time intervals within and between the groups. The value of glucose increased slightly in the group-II. Anaesthetic and surgical stress can lead to an increased secretion of adrenocortical hormone (ACTH) and glucocorticoids which contribute for rise in blood glucose level (Dikshit and Prasad, 1971; Mirakhur et al., 1984). The biochemical parameters also showed a nonsignificant difference at different time intervals within and between the groups.

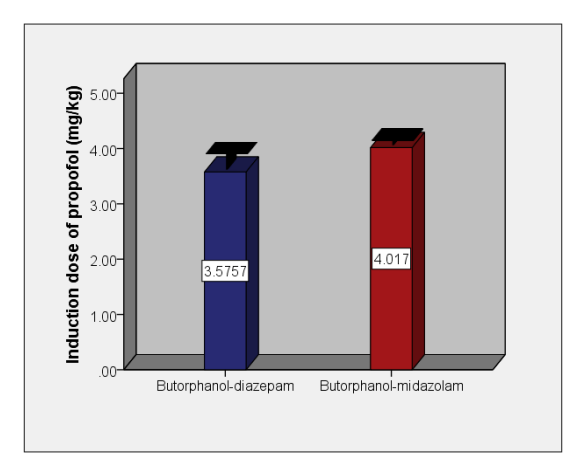

Fig. 1: Mean \pm SE values of induction dose of propofol in animals of group I \& II

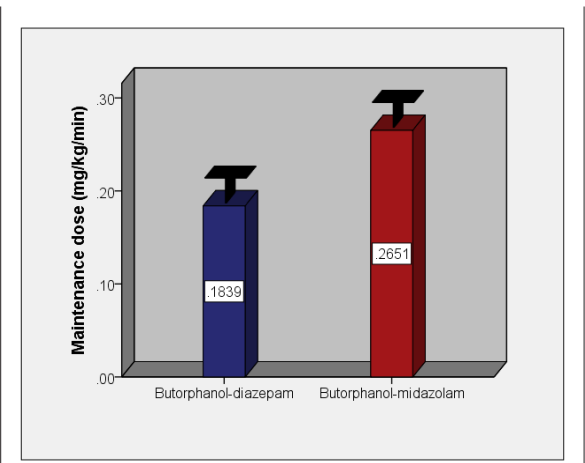

Fig. 2: Mean \pm SE values of maintenance dose of propofol in animals of group I \& II

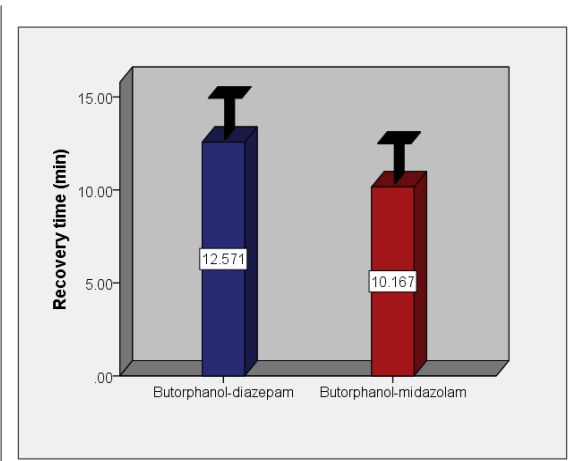

Fig. 3: Mean \pm SE values of recovery time (min) in animals of group I \& II 
Table 2: Mean \pm SE values of different physiological parameters in animals

\begin{tabular}{|c|c|c|c|c|c|}
\hline Parameter & Time (Min.) & Group I & Group II & F-value & P-value \\
\hline \multirow{6}{*}{ Rectal temperature $\left({ }^{0} \mathrm{~F}\right)$} & 0 & $101.91 \pm 0.25^{\mathrm{c}}$ & $100.20 \pm 0.49^{b}$ & 3.23 & 0.008 \\
\hline & 15 & $100.77 \pm 0.52^{b}$ & $99.50 \pm 0.56^{b}$ & 1.67 & 0.124 \\
\hline & 30 & $99.90 \pm 0.37^{\mathrm{ab}}$ & $99.0 \pm 0.45^{\mathrm{ab}}$ & 1.57 & 0.145 \\
\hline & 45 & $99.29 \pm 0.50^{\mathrm{a}}$ & $98.08 \pm 0.27^{\mathrm{a}}$ & \multirow[t]{3}{*}{0.025} & \multirow[t]{3}{*}{0.069} \\
\hline & F-value & 7.27 & 3.823 & & \\
\hline & $\mathrm{p}$-value & 0.001 & 0.026 & & \\
\hline \multirow{6}{*}{ Pulse rate (beats/min) } & 0 & $107.71 \pm 7.65$ & $89.50 \pm 9.26$ & 1.531 & 0.154 \\
\hline & 15 & $141.29 \pm 4.51$ & $130.50 \pm 12.00$ & 0.894 & 0.39 \\
\hline & 30 & $141.0 \pm 6.27$ & $135.0 \pm 9.42$ & 0.545 & 0.597 \\
\hline & 45 & $139.29 \pm 12.74$ & $123.83 \pm 13.07$ & \multirow[t]{3}{*}{0.843} & \multirow[t]{3}{*}{0.417} \\
\hline & F-value & 3.847 & 3.488 & & \\
\hline & $\mathrm{p}$-value & 0.022 & 0.035 & & \\
\hline \multirow{6}{*}{ Respiratory rate (Breaths/min) } & 0 & $83.14 \pm 14.83$ & $75.33 \pm 13.63$ & 0.383 & 0.709 \\
\hline & 15 & $45.71 \pm 9.18$ & $35.67 \pm 5.45$ & 0.899 & 0.388 \\
\hline & 30 & $53.86 \pm 17.82$ & $28.50 \pm 5.44$ & 1.267 & 0.231 \\
\hline & 45 & $50.86 \pm 18.35$ & $25.83 \pm 5.86$ & \multirow[t]{3}{*}{1.211} & \multirow[t]{3}{*}{0.251} \\
\hline & F-value & 1.183 & 7.596 & & \\
\hline & p-value & 0.337 & 0.001 & & \\
\hline \multirow{5}{*}{ Mean arterial pressure $(\mathrm{mmHg})$} & 15 & $94.57 \pm 4.04$ & $92.67 \pm 6.12$ & 0.267 & 0.795 \\
\hline & 30 & $101.14 \pm 5.96$ & $99.17 \pm 4.04$ & 0.265 & 0.796 \\
\hline & 45 & $102.43 \pm 6.35$ & $108.67 \pm 5.26$ & \multirow[t]{3}{*}{0.74} & \multirow[t]{3}{*}{0.475} \\
\hline & F-value & 0.578 & 2.383 & & \\
\hline & p-value & 0.571 & 0.126 & & \\
\hline \multirow{5}{*}{$\mathrm{SpO}_{2}(\%)$} & 15 & $90.00 \pm 3.08$ & $89.67 \pm 0.56$ & 0.098 & 0.923 \\
\hline & 30 & $90.57 \pm 1.76$ & $92.50 \pm 1.09$ & 0.894 & 0.39 \\
\hline & 45 & $92.29 \pm 1.36$ & $91.17 \pm 0.95$ & \multirow[t]{3}{*}{0.653} & \multirow[t]{3}{*}{0.527} \\
\hline & F-value & 0.295 & 2.523 & & \\
\hline & p-value & 0.748 & 0.114 & & \\
\hline
\end{tabular}

\section{CONCLUSION}

The present study indicated that both preanaesthetic combinations of Atropine-Butorphanol-Diazepam (A-B-D) and Atropine-Butorphanol-Midazolam (A-B-M) showed non-significant and transient alterations in different clinico-physiological and haemato-biochemical parameters with a marked dose sparing action on the propofol required for induction and maintenance in dogs; with group I (A-B-D) slightly better than group II (A-B-M).

\section{REFERENCES}

Beths, T. 2008. Total intravenous anaesthesia in dogs: Development of a target-controlled infusion (TCI) scheme for propofol. $\mathrm{PhD}$ thesis, Department of Companion
Animal Sciences, University of Glasgow, http://theses.gla. ac.uk/354/01/2008bethsphd.pdf.

De Vries, A., Taylor, P.M., Troughton, G., Liu, B., Fowden, A. L. and Sear, J.W. 2013. Real time monitoring of propofol blood concentration in ponies anaesthetized with propofol and ketamine. J. Vet. Pharm. Ther., 36(3): 258-266.

Dikshit, V.C. and Prasad, J. 1971. The influence of surgical trauma on blood glucose levels during anaesthesia. Indian $J$. Anaesth., 19: 111.

Jimenez, C.P., Mathis, A., Mora, S.S., Brodbelt, D. and Alibhai, H. 2012. Evaluation of the quality of the recovery after administration of propofol or alfaxalone for induction of anaesthesia in dogs anaesthetized for magnetic resonance imaging. Vet. Anaesth. Analg., 39(2):151-159.

Khandekar, G.S., Sarkate, L.B. and Bendale, K.R. 2015. Physiological and haemato-biochemical changes under 
propofol and halothane anaesthesia in dogs undergoing laparoscopic procedures. Indian J. Vet. Surg., 36(1): 17-20.

Koc, J.C., Payton, M.E. and White, A.G. 2006. Effects of intravenous diazepam or microdose medetomidine on propofol-induced sedation in dogs. J. Am. Anim. Hosp. Assoc., 42: 18-27.

Kuo, W.C. and Keegan, R.D. 2004. Comparative cardiovascular, analgesic and sedative effects of medetomidine, medetomidine hydromorphone and medetomidine-butorphanol in dogs. Am. J. Vet. Res., 65: 931-937.

Kushwaha, J.P., Malik, V. and Singh, B. 2012. Evaluation of midazolam and propofol in different combinations for clinical anaesthesia in dogs. Indian J. Vet. Surg., 33(2): 77-81.

Lemke, K.A. 2007. Anticholinergics and sedatives. Lumb \& Jones, Veterinary Anesthesia and Analgesia. Fourth edition. Blackwell Publishing Ltd., Oxford, pp. 203-239.

Mirakhur, K.K., Sobti, V.K. and Nigam, J.M. 1984. Effect of thiopentone anaesthesia in plasma cortisol in buffalo calves. Indian J. Vet. Surg., 3: 86-88.

Mutoh, T., Nishimura, R., Kim, H., Matsunaga, S. and Sasaki, N. 1997. Cardiopulmonary effects of sevoflurane, compared with halothane, enflurane and isoflurane in dogs. Am. J. Vet. Res., 58: 885-890.

Rebecca, R. and Kate, B.W. 2015. The effects of diazepam or midazolam on the dose of propofol required to induce anaesthesia in cats. Vet. Anaes. Analg., 42(5): 493-501.
Sano, T., Nishimura, R., Mochizuki, M. and Sasaki, N. 2003. Effects of midazolam-butorphanol, acepromazinebutorphanol and medetomidine on an induction dose of propofol and their compatibility in dogs. J Vet. Med. Sci., 65(10): 1141-1143.

Surbhi, Kinjavdekar, P., Amarpal, Aithal, H.P., Pawde, A.M., Pathak, M.C., Borena, B.M. and Malik, V. 2010. Physiological and biochemical effects of medetomidine-butorphanol propofol anaesthesia in dogs undergoing orthopaedic surgery. Indian. J. Vet. Surg., 31(2): 101-104.

Suthar, D.N., Mistry, J.N., Tyagi, S.K., Jhala, S.K., Bhatt, R.H. and Dabas, V.S. 2018. Evaluation of propofol/thiopentone and isoflurane anaesthesia in dogs. Indian J. Vet. Surg., 39(2): 105-109.

Thurmon, J.C. and Short, C.E. 2007. History and Overview of Veterinary Anesthesia. Tranquilli W.J., Thurmon J.C. and Grimm K.A. (editors). Lumb \& Jones, Veterinary Anesthesia and Analgesia. Fourth edition. Blackwell Publishing Ltd., Oxford, pp. 3-6.

Vannatta, M.E. and Rex, D.K. 2006. Propofol alone titrated to deep sedation versus propofol in combination with opioids and/or benzodiazepines and titrated to moderate sedation for colonoscopy. Amer. J. Gastroenterol., 101: 2209-2217.

Waelbers, T., Vermoere, P. and Polis, I. 2009. Total intravenous anesthesia in dogs: Review. Vlaams Diergeneeskundig Tijdschrift. 78: 160-169. 
